\author{
Bogustaw Tymoniuk ${ }^{\prime *}$, Pawet Zmora ${ }^{2 *}$, Julia Latowska ${ }^{2}$, Adriana Grabowska ${ }^{2}$, \\ Adam Ciesiotka ${ }^{2}$ Pawet Joachimiak², Grzegorz Figura', Maciej Borowiec ${ }^{3}$, Katarzyna Rolle ${ }^{2}$, \\ Luiza Handschuh², Agnieszka Fiszer ${ }^{2}$
}

\title{
GENETIC TESTS BASED ON THE RT-PCR REACTION IN THE DIAGNOSTICS OF SARS-CoV-2 INFECTION
}

\author{
TESTY GENETYCZNE OPARTE O REAKCJĘ RT-PCR \\ W DIAGNOSTYCE ZAKAŻENIA SARS-CoV-2
}
${ }^{1}$ Medical University of Lodz, Department of Immunology, Rheumatology and Allergy Uniwersytet Medyczny w Łodzi, Klinika Immunologii, Reumatologii i Alergii ${ }^{2}$ Institute of Bioorganic Chemistry Polish Academy of Sciences Instytut Chemii Bioorganicznej Polskiej Akademii Nauk
${ }^{3}$ Medical University of Lodz, Department of Clinical Genetics, Chair of Clinical and Laboratory Genetics Uniwersytet Medyczny w Łodzi, Katedra Genetyki Klinicznej i Laboratoryjnej, Zakład Genetyki Medycznej "equal contribution / równorzędni współautorzy

\begin{abstract}
INTRODUCTION. Since the SARS-CoV-2 emergence in 2019/2020, at least 158 million infections with this pathogen have been recorded, of which 3.29 million infected people have died. Due to the non-specific symptoms of SARS-CoV-2 infection, laboratory tests based on RT-PCR (reverse transcription and polymerase chain reaction) are mainly used in the diagnosis of COVID-19 disease.

AIM. The aim of this study is to compare the molecular tests available on the Polish market for the diagnosis of SARS-CoV2 infection.

RESULTS. Based on the data provided by the manufacturers and the performed laboratory analyses, we have shown that the available diagnostic kits differ mainly in the sensitivity and duration of the reaction.

CONCLUSION. due to the ongoing COVID-19 pandemic, the indicated parameters are key to effective control of the spread of SARS-CoV2, and therefore should be mainly taken into account when choosing and purchasing by diagnostic centres.
\end{abstract}

Keywords: diagnostic tests; SARS-CoV-2; RT-PCR; efficacy

\section{STRESZCZENIE}

WSTĘP. Od momentu pojawienia się SARS-CoV-2 na przełomie 2019 i 2020 roku, zanotowano co najmniej 158 milionów zakażeń tym patogenem, z czego 3,29 miliona zakażonych osób zmarło. Ze względu na niespecyficzne objawy zakażenia SARS-CoV-2, w diagnostyce choroby COVID-19 stosowane są głównie testy laboratoryjne oparte o reakcję RT-PCR (odwrotna transkrypcja i łańcuchowa reakcja polimerazy).

CEL. Celem niniejszej pracy jest porównanie dostępnych na polskim rynku testów molekularnych do diagnostyki zakażenia SARS-CoV2.

WYNIKI. Na podstawie danych udostępnionych przez producentów oraz wykonanych analiz laboratoryjnych wykazaliśmy, iż dostępne zestawy diagnostyczne różnią się głównie czułością oraz czasem trwania reakcji.

WNIOSKI. Ze względu na trwającą pandemię COVID-19, wskazane parametry są kluczowymi do skutecznej kontroli rozprzestrzeniania się SARS-CoV2, tym samym powinny być głównie brane pod uwagę przy wyborze i zakupie przez centra diagnostyczne.

Słowa kluczowe: testy diagnostyczne; SARS-CoV-2; RT-PCR; skuteczność 


\section{INTRODUCTION}

According to the World Health Organization (WHO), lower respiratory tract infections are among the ten most common causes of death (1). In 2016, there were approximately 336.5 million cases of respiratory infections and 2.6 million people died (2). The most common causes of lower respiratory tract infections and related deaths worldwide were: Streptococcus pneumoniae, influenza viruses (IAVs), respiratory syncytial virus (RSV) and Haemophilus influenzae type b (2). In 2018, 1,315 cases of Streptococcus pneumoniae infection, 116 cases of Haemophilus influenzae infection and 5.2 million cases of influenzalike infections were detected in Poland (3). In 2020, the newly discovered virus SARS-CoV-2 (severe acute respiratory syndrome coronavirus 2), causing COVID-19 (coronavirus disease 2019), joined the group of pathogens most often causing respiratory infections. Since its appearance, SARS-CoV-2 has caused over 158 million infections and approximately 3.29 million deaths (1), triggering a second pandemic in the 21 st century.

In most cases, respiratory tract infections manifest themselves with similar symptoms, e.g. cough, fever, headache, weakness, and muscle and joint pain. (4). For this reason, diagnosis and identification of the disease agent on the basis of symptoms alone is impossible. Therefore, in order to make a proper diagnosis, apply an appropriate drug therapy, e.g. oseltamivir to treat influenza virus infection (4), and control the spread of a pathogen, e.g. SARS-CoV-2, laboratory tests should be performed. Currently, there are three types of tests on the market which can be used in the diagnosis of SARS-CoV-2 infection: antigen tests and genetic tests directly detecting the presence of the virus in the respiratory tract $(5,6)$ and serological tests detecting anti-SARS-CoV-2 antibodies. Due to the specificity of serological tests, they are not useful in detecting an ongoing SARS-CoV-2 infection and are only used in retrospective diagnostics $(7,8)$. Serological tests have already been discussed in detail in the Epidemiological Review (7) and will therefore not be described in this article.

The mechanism of action of antigen tests, the so-called rapid tests, consists in detecting specific SARS-CoV-2 proteins in the collected swab using immunochromatography. The advantage of this diagnostic method is the simplicity of execution, quick reaction time and the possibility of carrying out the test, e.g. at the patient's bedside, the so-called diagnostics of 'point of care' (5-7). However, it should be emphasized, that antigen tests are characterized by a lower sensitivity than genetic tests (5) and therefore, according to the manufacturers' recommendations,

\section{WSTEP}

Według Światowej Organizacji Zdrowia, jednymi z dziesięciu najczęstszych przyczyn zgonów są zakażenia dolnych dróg oddechowych (1). W 2016 roku odnotowano około 336,5 milionów przypadków infekcji dróg oddechowych, z czego około 2,6 miliona osób zmarło (2). Najczęstszą przyczyną zakażenia dolnych dróg oddechowych oraz związanych z nimi zgonów na świecie były: Streptococcus pneumoniae, wirusy grypy (IAVs), syncytialny wirus oddechowy (RSV) oraz Haemophilus influenzae typ b (2). W 2018 roku w Polsce wykryto 1315 przypadków zakażenia Streptococcus pneumoniae, 116 przypadków zakażenia Haemophilus influenzae oraz 5,2 miliona przypadków zakażeń grypopodobnych (3). Natomiast w 2020 roku do grona patogenów najczęściej wywołujących zakażenia dróg oddechowych dołączył nowo odkryty wirus SARS-CoV-2 (severe acute respiratory syndrome coronavirus 2), wywołujący chorobę COVID-19. Od momentu pojawienia się SARS-CoV-2 wywołał ponad 158 milionów zakażeń oraz doprowadził do około 3,29 milionów zgonów (1), tym samym wywołując drugą pandemię w XXI wieku.

W większości przypadków zakażenia dróg oddechowych manifestują się podobnymi objawami, np. kaszlem, gorączką, bólem głowy, osłabieniem oraz bólami mięśniowo-stawowymi (4). Z tego powodu diagnoza oraz identyfikacja czynnika chorobotwórczego na podstawie samych objawów jest niemożliwa. Zatem w celu postawienia diagnozy, zastosowania odpowiedniej terapii lekowej, np. użyciu oseltamiviru w leczeniu zakażenia wirusem grypy (4), oraz kontroli rozprzestrzeniania się patogenu, np. SARS-CoV-2 w dobie pandemii, należy wykonać testy laboratoryjne. Obecnie na rynku dostępne są 3 rodzaje testów wykorzystywanych w diagnostyce zakażenia wirusem SARS-CoV-2: testy antygenowe i testy genetyczne bezpośrednio wykrywające obecność wirusa w drogach oddechowych $(5,6)$ oraz testy serologiczne wykrywające przeciwciała anty-SARS-CoV-2. Ze względu na specyfikę testów serologicznych, nieprzydatne są one w wykrywaniu trwającego zakażenia SARS-CoV-2 i służą jedynie w diagnostyce retrospektywnej $(7,8)$. Testy serologiczne zostały już szczegółowo omówione w Przeglądzie Epidemiologicznym (7) i stąd nie będą omawiane w niniejszym artykule.

Mechanizm działania testów antygenowych, tzw. szybkich testów kasetkowych, polega na wykryciu specyficznych białek SARS-CoV-2 w pobranym wymazie przy użyciu immunochromatografii. Zaletą tej metody diagnostycznej jest prostota wykonania, szybki czas reakcji oraz możliwość przeprowadzenia testu np. przy łóżku pacjenta, tzw. diagnostyka 'point of care' (5-7). Należy jednak podkreślić, iż testy antygenowe 
they should be used only in symptomatic patients. For this reason, the result of the rapid test should be confirmed using genetic tests, which are the gold diagnostic standard $(5,6,9)$. The mechanism of genetic testing is based on the detection of SARS-CoV-2 genetic material in the collected sample using SARS-CoV-2 unique and specific primers with reverse transcription (RT) and polymerase chain reaction (PCR) $(5,9)$. The undoubted advantage of this method is high sensitivity and specificity, as well as high throughput and the ability to control the diagnostic process by introducing internal reaction control and swab control $(5,9,10)$. However, it should be emphasized, that the above features largely depend on several factors, such as enzymes, primers and probes, and may differ between commercially available assays. Moreover, the admission of diagnostic tests to the European market and the granting of the CE-IVD certificate is based solely on declarations and analyses performed by the manufacturers themselves, hence independent testing of the effectiveness of the diagnostic kits is needed.

\section{AIM OF STUDY}

The aim of this study is to compare the genetic tests based on the RT-PCR reaction used in the diagnosis of SARS-CoV-2 infection available on the Polish market. The comparison was made on the basis of publications, information provided by manufacturers and test results obtained in two independent units (SPZOZ Central Clinical Hospital of the Medical University in Łódź and the Institute of Bioorganic Chemistry Polish Academy of Sciences in Poznań).

\section{MATERIAL AND METHODS}

In order to compare selected genetic tests, we analysed documents available on the websites of: World Health Organization (WHO, www.who.int), European Center for Disease Prevention and Control (ECDC, www.ecdc.europa.eu), Food and Drug Administration (FDA, www.fda.gov) as well as information provided on the websites by the manufacturers of selected tests: Bosphore Novel Coronavirus (2019-nCoV) Detection Kit (www.anatoliageneworks.com), VIASURE SARS-CoV-2 Real Time PCR Detection Kit (www. certest.es), DiaPlexQ ${ }^{\mathrm{TM}}$ Novel Coronavirus (2019nCoV) Detection Kit (www.solgent.com), GeneFinder COVID-19 Plus RealAmp Kit (www.osanghc.com), Liferiver Novel Coronavirus (2019-nCoV) Multiplex RT-PCR (www.liferiverbiotech.com), Vazyme 2019-Novel Coronavirus (2019-nCoV) Triplex RTqPCR (www.vazymebiotech.com), Vitassay qPCR SARS-CoV-2 (www.vitassay.com), MediPAN 2G+ FAST COVID test (www.medicofarma.pl). odznaczają się niższą czułością niż testy genetyczne (5) i z tego względu, zgodnie z rekomendacjami producentów, powinny być używane wyłącznie u pacjentów pełnoobjawowych. $Z$ tego też względu wynik szybkiego testu kasetkowego powinien być potwierdzony za pomocą testów genetycznych, będących złotym standardem diagnostycznym $(5,6,9)$. Mechanizm działania testów genetycznych polega na wykryciu materiału genetycznego SARS-CoV-2 w pobranej próbce przy użyciu unikatowych i specyficznych wyłącznie dla SARSCoV-2 starterów na drodze odwrotnej transkrypcji (RT, reverse transcription) oraz łańcuchowej reakcji polimerazy (PCR, polymerase chain reaction) $(5,9)$. Niewątpliwą zaletą tej metody jest wysoka czułość i swoistość, jak również wysoka przepustowość oraz możliwość kontrolowania procesu diagnostycznego poprzez wprowadzenie wewnętrznej kontroli reakcji oraz kontroli wymazu $(5,9,10)$. Należy jednak podkreślić, iż powyższe cechy zależą w dużej mierze od kilku czynników, m.in. zastosowanych enzymów, starterów i sond oraz mogą różnić się między komercyjnie dostępnymi testami. Co więcej, dopuszczenie testów diagnostycznych na rynek europejski oraz przyznanie certyfikatu CE-IVD opiera się wyłącznie na deklaracji oraz analizach wykonanych przez samych producentów, stąd niezmiernie ważne są niezależne badania skuteczności stosowanych zestawów diagnostycznych.

\section{CEL PRACY}

Celem niniejszej pracy jest porównanie dostępnych na polskim rynku testów genetycznych opartych o reakcję RT-PCR wykorzystywanych w diagnostyce zakażenia wirusem SARS-CoV-2. Porównanie przeprowadzono na podstawie dostępnych publikacji , informacji podanych przez producentów oraz wyników testów uzyskanych w dwóch niezależnych jednostkach (SPZOZ Centralny Szpital Kliniczny Uniwersytetu Medycznego w Łodzi oraz Instytut Chemii Bioorganicznej PAN w Poznaniu).

\section{MATERIAŁ I METODY}

W celu porównania wybranych testów genetycznych, przeprowadzono analizę dokumentów dostępnych na stronach internetowych: Światowej Organizacji Zdrowia (WHO, www.who.int), Europejskiego Centrum ds. Zapobiegania i Kontroli Chorób (ECDC, www.ecdc.europa.eu), Agencji Żywności i Leków (FDA, www.fda.gov) oraz producentów wybranych testów: Bosphore Novel Coronavirus (2019-nCoV) Detection Kit (www.anatoliageneworks.com), VIASURE SARS-CoV-2 Real Time PCR Detection Kit (www.certest.es), DiaPlexQ ${ }^{\mathrm{TM}}$ Novel Coronavirus (2019-nCoV) Detection Kit (www.solgent.com), Gene- 
In the next stage of the study, we randomly selected 40 samples from the persons diagnosed for SARSCoV-2 virus infection at the Laboratory of Transplant Immunology, SPZOZ Central Clinical Hospital of the Medical University in Łódź. At the mentioned Laboratory, viral RNA was isolated from selected samples using the Maxwell RSC Viral TNA kit and the Maxwell RSC 48 apparatus, then aliquoted and frozen at $-80^{\circ} \mathrm{C}$. Some aliquots were transported to IBCH PAS on dry ice. The genetic test for the presence of SARS-CoV-2 virus based on the RTPCR reaction was performed using the following kits: Bosphore Novel Coronavirus (2019-nCoV) Detection Kit, VIASURE SARS-CoV-2 Real Time PCR Detection Kit, DiaPlexQ ${ }^{\mathrm{TM}}$ Novel Coronavirus, Vazyme 2019-Novel Coronavirus (2019-nCoV) Triplex RT-qPCR and MediPAN 2G + FAST COVID test. Analyses were performed simultaneously in two independent laboratories using the AriaMx Real-Time PCR System (Agilent) and CFX96 Touch Real-Time PCR Detection System (Biorad).

\section{RESULTS}

In accordance with the requirements of Polish and European law, all commercially available kits for the diagnosis of COVID-19/SARS-CoV-2 infection are certified with IVD symbol and detect at least 2 viral genes (mostly ORFlab and N, Tab. I), and thus meet the recommendations of the National Institute of Public Health - National Institute of Hygiene in the field of molecular diagnostics of SARS-CoV-2 from April 24, 2020 (11). Moreover, all commercially available diagnostic tests are characterized by a sensitivity and specificity equal to or greater than $95 \%$ and a lack of cross-reactivity with other known pathogens such as IAVs, RSV, human metapneumovirus, Legionella spp. or Streptococcus pneumoniae (Table I). In addition, in all analysed kits it is possible to use genetic material isolated from the most common type of samples, i.e. nasopharyngeal swabs and throat swabs, and some manufacturers also allow the use of saliva or nasopharyngeal aspirates (Table I). It is also worth emphasizing that the analysed kits consist of probes conjugated with most common fluorophores, such as FAM, HEX, Cy5, what enables the diagnostic test performance on the most frequently used real-time PCR devices, e.g. ABI7500 Fast PCR System (Applied Biosystems), CFX96 PCR System (Biorad), AriaMx (Agilent) or LightCycler (Roche) (Table I). On the other hand, the analysed diagnostic tests differ mostly in terms of the smallest detectable amount of viral genetic material, the so-called detection limit as well as reaction time (Table I). The DiaplexQ 2019-nCoV (SolGent), Vazyme 2019-nCoV RT-qPCR (Nanjing
Finder COVID-19 Plus RealAmp Kit (www.osanghc. com), Liferiver Novel Coronavirus (2019-nCoV) Multiplex RT-PCR (www.liferiverbiotech.com), Vazyme 2019-Novel Coronavirus (2019-nCoV) Triplex RT-qPCR (www.vazymebiotech.com), Vitassay qPCR SARS-CoV-2 (www.vitassay.com), MediPAN 2G+ FAST COVID test (www.medicofarma.pl).

W kolejnym etapie badań losowo wybrano 40 próbek od osób diagnozowanych w kierunku zakażenia wirusem SARS-CoV-2 w ramach działalności Pracowni Immunologii Transplantacyjnej SPZOZ Centralnego Szpitala Klinicznego Uniwersytetu Medycznego w Łodzi. W Pracowni Immunologii Transplantacyjnej z wybranych próbek wyizolowano RNA za pomocą zestawu Maxwell RSC Viral TNA oraz aparatu Maxwell RSC 48, a następnie rozporcjowano, zamrożono $\mathrm{w}-80^{\circ} \mathrm{C}$ i część przetransportowano do ICHB PAN na suchym lodzie._ Test genetyczny na obecność wirusa SARS-CoV-2 oparty o reakcję RT-PCR wykonano przy użyciu następujących zestawów: Bosphore Novel Coronavirus (2019-nCoV) Detection Kit, VIASURE SARS-CoV-2 Real Time PCR Detection Kit, DiaPlexQ ${ }^{\text {TM }}$ Novel Coronavirus, Vazyme 2019-Novel Coronavirus (2019-nCoV) Triplex RT-qPCR oraz MediPAN 2G+ FAST COVID test. Analizy zostały wykonane jednocześnie $\mathrm{w}$ dwóch niezależnych laboratoriach przy użyciu aparatów AriaMx Real-Time PCR System (Agilent) oraz CFX96 Touch Real-Time PCR Detection System (Biorad).

\section{WYNIKI}

Zgodnie z wymogami polskiego oraz europejskiego prawa wszystkie dostępne komercyjnie zestawy do diagnostyki zakażenia SARS-CoV-2/COVID-19 posiadają certyfikat IVD oraz wykrywają co najmniej 2 geny wirusa (najczęściej ORFlab oraz N, Tab. I), spełniając tym samym rekomendacje Narodowego Instytutu Zdrowia Publicznego - Państwowego Zakładu Higieny $w$ zakresie diagnostyki molekularnej SARS-CoV-2 z 24.04.2020 roku (11). Ponadto wszystkie dostępne komercyjnie testy diagnostyczne cechują się czułością i swoistością równą lub wyższą niż 95\% oraz brakiem reaktywności krzyżowej z innymi dotychczas poznanymi patogenami, takimi jak IAVs, RSV, ludzki metapneumowirus, Legionella spp. czy Streptococcus pneumoniae (Tab. I). Co więcej, we wszystkich analizowanych zestawach możliwe jest wykorzystanie materiału genetycznego izolowanego $\mathrm{z}$ najczęstszego rodzaju próbek, tj. wymazów z nosogardzieli oraz wymazów z gardła, przy czym niektórzy producenci dopuszczają również wykorzystanie izolatów ze śliny oraz aspiratów z nosogardzieli (Tab. I). Wartym podkreślenia jest również fakt, iż producenci analizowanych testów wykorzystali najczęściej 
Bogusław Tymoniuk, Paweł Zmora, Julia Latowska et al.

\begin{tabular}{|c|c|c|c|c|c|c|c|c|}
\hline 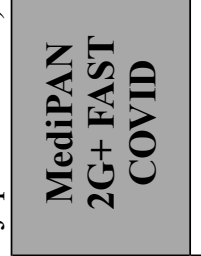 & 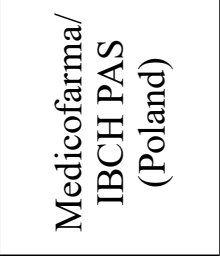 & $\stackrel{\infty}{\infty}$ & 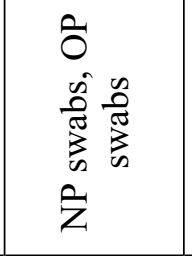 & $\begin{array}{l}n \\
\frac{\pi}{\pi} \\
\frac{\pi}{0} \\
\frac{\pi}{0}\end{array}$ & 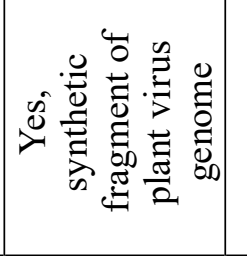 & $\stackrel{\circ}{z}$ & ڤे & बें \\
\hline 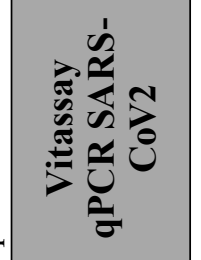 & 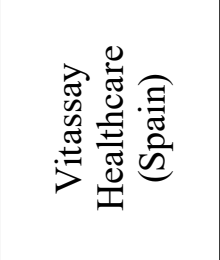 & $\stackrel{\infty}{\varnothing}$ & 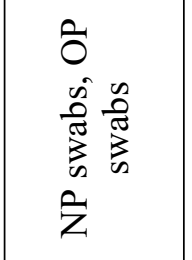 & $\begin{array}{l}z \\
\frac{\pi}{\pi} \\
\frac{\pi}{T} \\
\frac{0}{0}\end{array}$ & 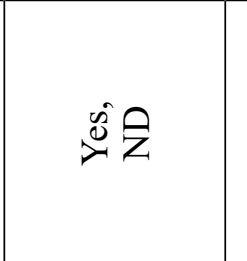 & $\stackrel{8}{z}$ & . & $\frac{.50}{.00}$ \\
\hline 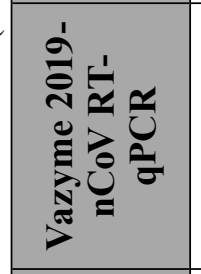 & 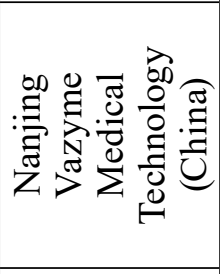 & $\stackrel{\infty}{\nu}$ & 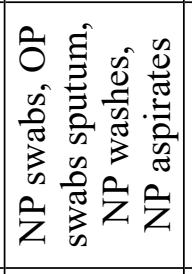 & $\begin{array}{l}z \\
\frac{0}{\sigma} \\
\frac{\sigma}{I} \\
\frac{1}{0}\end{array}$ & : & $\underset{z}{\stackrel{z}{z}}$ & 定 & ڤั̀े \\
\hline 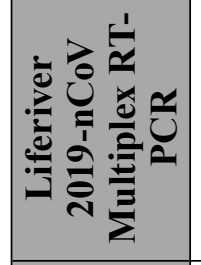 & 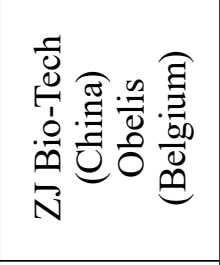 & $\stackrel{\infty}{\nu}$ & 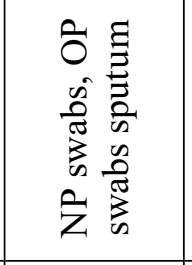 & 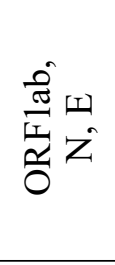 & 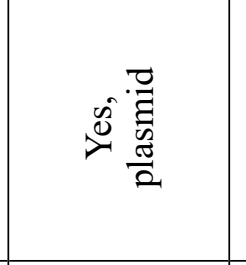 & z̊ & $\begin{array}{l}\text { ลें } \\
\text { ลे }\end{array}$ & $\frac{\stackrel{0}{\infty}}{\stackrel{\infty}{a}}$ \\
\hline 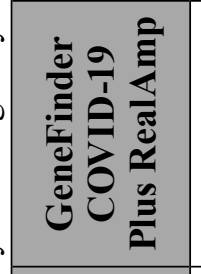 & 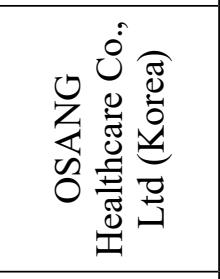 & 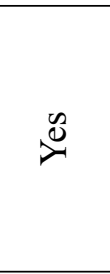 & 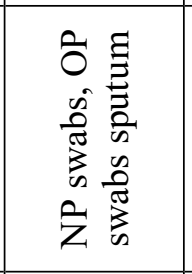 & 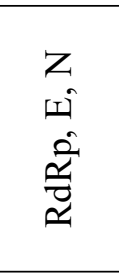 & : & 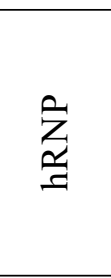 & ถั & 条 \\
\hline 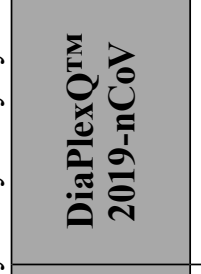 & 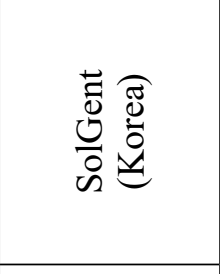 & 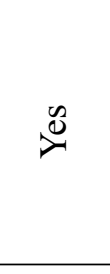 & 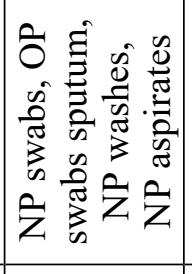 & $\begin{array}{l}z \\
\frac{\sigma}{\pi} \\
\frac{\sigma}{0} \\
0\end{array}$ & 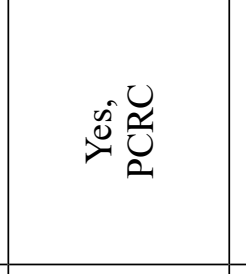 & z & ஃे & $\begin{array}{l}\text { bे } \\
\text { ڤं } \\
\text { ì }\end{array}$ \\
\hline 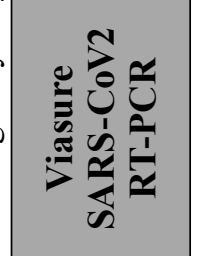 & 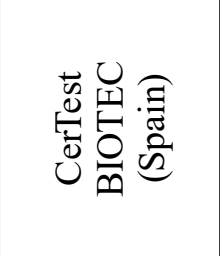 & 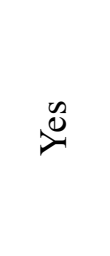 & 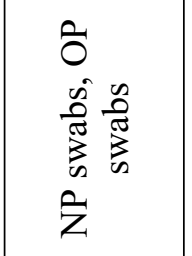 & $\begin{array}{l}z \\
\frac{\sigma}{\pi} \\
\frac{\sigma}{0} \\
0\end{array}$ & $\stackrel{0}{0} \mathrm{z}$ & $\stackrel{\circ}{z}$ & $\begin{array}{l}\text { iे } \\
\hat{\sigma}\end{array}$ & $\begin{array}{l}\stackrel{2}{\alpha} \\
\text { مे }\end{array}$ \\
\hline 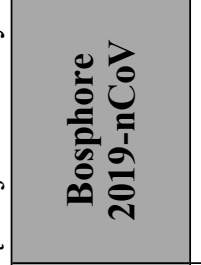 & 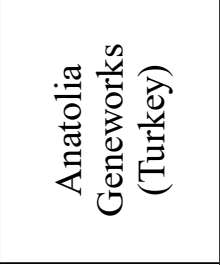 & $\ddot{\nu}$ & 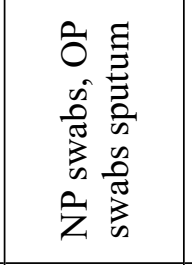 & $\begin{array}{l}\text { ㅍ } \\
\frac{0}{\pi} \\
\frac{\pi}{1} \\
\frac{0}{0}\end{array}$ & 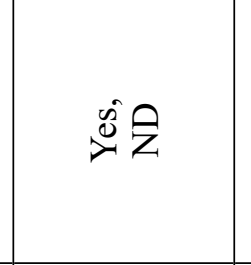 & z & ڤ̆ & $\begin{array}{l}\stackrel{\circ}{\circ} \\
\text { ลे }\end{array}$ \\
\hline & 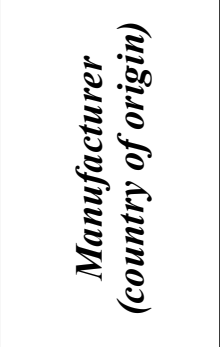 & है & 气ั้ & 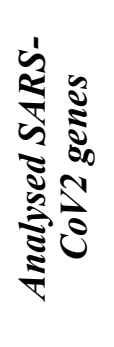 & 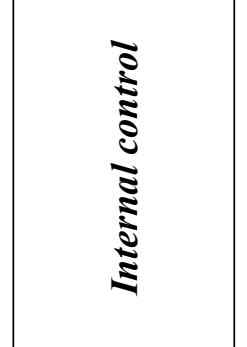 & है & 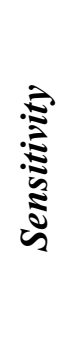 & 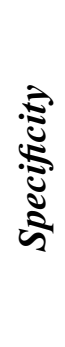 \\
\hline
\end{tabular}




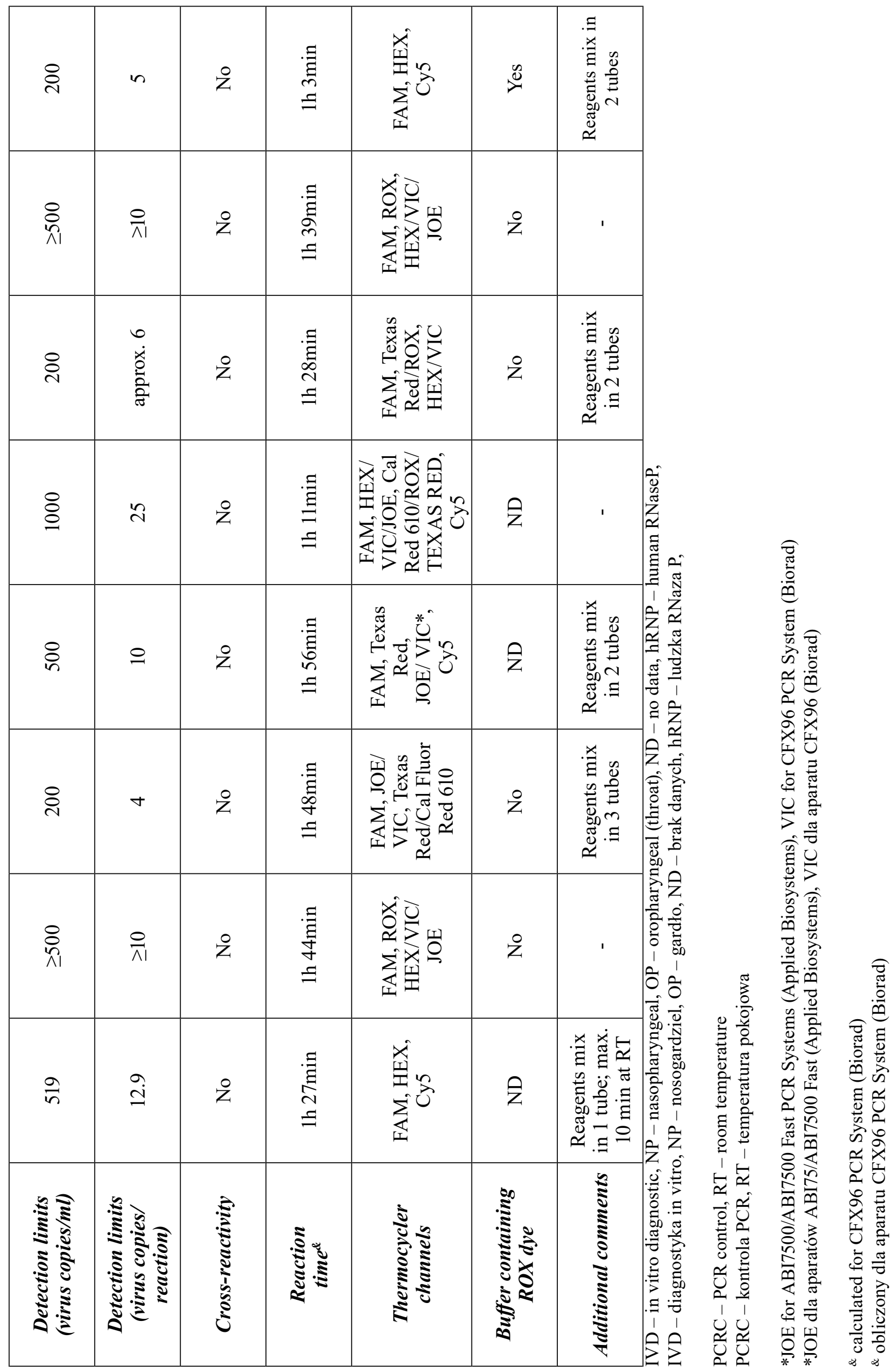


Vazyme Medical Technology) and MediPAN 2G + FAST COVID (Medicofarma/IBCH PAS) has the lowest detection limit, i.e. 200 copies / $\mathrm{ml}$. The fastest diagnostic result is obtained with MediPAN 2G+ FAST COVID (Medicofarma/IBCH PAS) and Liferiver 2019-nCoV Multiplex RT-PCR (ZJ Bio-Tech/Obelis). stosowane fluorofory, takie jak FAM, HEX, Cy5, tym samym umożliwiając korzystanie $\mathrm{z}$ oferowanych zestawów diagnostycznych na najpowszechniej używanych aparatach do PCR w czasie rzeczywistym, np. ABI7500 Fast PCR System (Applied Biosystems), CFX96 PCR System (Biorad), AriaMx (Agilent) czy też LightCycler Instruments (Roche) (Tab. I). Z dru-

Dositive $\square$ Negative

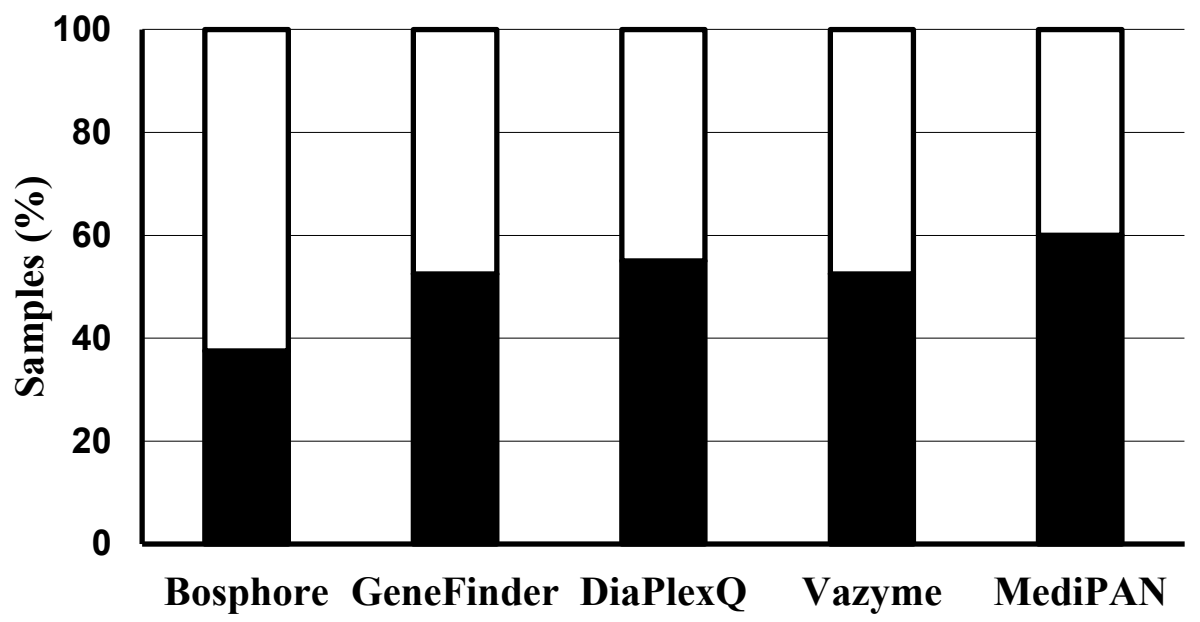

Figure 1. Detection of SARS-CoV-2 infection in the tested samples

Laboratory tests, carried out on 40 randomly selected samples from patients diagnosed for SARS-CoV-2 virus infection, showed the presence of the pathogen in: 15 (Bosphore), 21 (GeneFinder), 22 (DiaPlexQ), 21 (Vazyme) and 24 (MediPAN ) people (Fig. 1). In the case of two samples (397a14 and 397a15, Table II), the MediPAN kit identified SARS-CoV-2 infection, and in accordance with the manufacturer's recommendations, this result should be confirmed by analysis of a swab taken within the next 2 days or in accordance with WHO recommendations, if it is not possible to collect the biological material again, the positive result should be confirmed using another test or sequencing. For sample 397a14, a positive result was confirmed using the DiaPlexQ kit and an AriaMx system (Agilent). On the other hand, the presence of SARS-CoV-2 in sample $397 \mathrm{a} 15$ was not confirmed with other diagnostic kits, and the amount of material did not allow sequencing, which may suggest a false positive result caused by e.g. contamination of the sample. The obtained results may indicate a higher sensitivity of the MediPAN and DiaPlexQ sets, according to the information provided by the manufacturers, compared to the other diagnostic sets tested. On the other hand, a high number of falsenegative results for the Bosphore kit may indicate a lower sensitivity of this test compared to the others. This may be due to the limited number of PCR cycles recommended by the manufacturer, i.e. 35 , and the low viral load of some swabs (Table II). giej strony, analizowane testy diagnostyczne różnią się między sobą najbardziej pod kątem najmniejszej wykrywalnej ilości wirusowego materiału genetycznego, tzw. limitu detekcji, oraz czasu reakcji (Tab. I). Najniższym limitem detekcji, tj. $200 \mathrm{kopii} / \mathrm{ml}$, wyróżniają się testy: DiaplexQ 2019-nCoV (SolGent), Vazyme 2019nCoV RT-qPCR (Nanjing Vazyme Medical Technology) oraz MediPAN 2G+ FAST COVID (Medicofarma/ Instytut Chemii Bioorganicznej PAN). Z kolei wynik diagnostyczny najszybciej uzyskiwany jest przy użyciu MediPAN 2G+ FAST COVID (Medicofarma/ Instytut Chemii Bioorganicznej PAN) oraz Liferiver 2019-nCoV Multiplex RT-PCR (ZJ Bio-Tech/Obelis).

Badania laboratoryjne, przeprowadzone na 40 losowo wybranych próbkach od osób diagnozowanych w kierunku zakażenia wirusem SARS-CoV-2, wykazały obecność patogenu u: 15 (Bosphore), 21 (GeneFinder), 22 (DiaPlexQ), 21 (Vazyme) oraz 24 (MediPAN) osób (Fig. 1). W przypadku 2 próbek (397a14 oraz 397a15, Tab. II), zestaw MediPAN zidentyfikował zakażenie SARS-CoV-2, przy czym zgodnie z rekomendacjami producenta wynik ten powinien być potwierdzony analizą wymazu pobranego w ciągu kolejnych 2 dni lub zgodnie z rekomendacjami WHO, w przypadku braku możliwości ponownego pobrania materiału biologicznego, wynik pozytywny powinien zostać potwierdzony przy użyciu innego testu lub sekwencjonowania.W przypadku próbki 397a14, wynik pozytywny potwierdzono przy użyciu zestawu DiaPlexQ oraz 
Table II. The Cq value and diagnostic results for the chosen samples analysed with selected genetic tests

Tabela II. Wartości Cq oraz wynik diagnostyczny dla wybranych próbek przy użyciu wybranych testów genetycznych

\begin{tabular}{|c|c|c|c|c|c|c|c|c|c|c|c|}
\hline \multirow{2}{*}{ Sample } & \multicolumn{2}{|c|}{ Bosphore $^{*}$} & \multicolumn{3}{|c|}{ GeneFinder* } & \multicolumn{2}{|c|}{ DiaPlexQ* } & \multicolumn{2}{|c|}{ Vazyme $^{*}$} & \multicolumn{2}{|c|}{ MediPAN $^{* *}$} \\
\hline & ORFlab & $\mathrm{E}$ & $\mathrm{RdRp}$ & $\mathrm{E}$ & $\mathrm{N}$ & $\mathrm{N}$ & ORF1a & ORF1al & $\mathrm{N}$ & ORF1ab & S \\
\hline \multirow{2}{*}{$397 \mathrm{a} 8$} & 29.19 & 28.58 & 27.85 & 28.53 & 26.09 & 29.26 & 27.56 & 25.42 & 24.55 & 26.44 & 26.01 \\
\hline & \multicolumn{2}{|c|}{ Positive } & \multicolumn{3}{|c|}{ Positive } & \multicolumn{2}{|c|}{ Positive } & \multicolumn{2}{|c|}{ Positive } & \multicolumn{2}{|c|}{ Positive } \\
\hline \multirow{2}{*}{$397 \mathrm{a} 9$} & $\mathbf{N} / \mathbf{A}$ & N/A & 36.97 & 39.6 & 31.14 & 37.7 & 34.43 & 31.13 & 28.91 & 32.71 & 31.86 \\
\hline & \multicolumn{2}{|c|}{ Negative } & \multicolumn{3}{|c|}{ Positive } & \multicolumn{2}{|c|}{ Positive } & \multicolumn{2}{|c|}{ Positive } & \multicolumn{2}{|c|}{ Positive } \\
\hline \multirow{2}{*}{$397 \mathrm{a} 10$} & N/A & N/A & 37.54 & N/A & 33.56 & 37.95 & 36.18 & 32.79 & 31.85 & 33.64 & 32.89 \\
\hline & \multicolumn{2}{|c|}{ Negative } & \multicolumn{3}{|c|}{ Positive } & \multicolumn{2}{|c|}{ Positive } & \multicolumn{2}{|c|}{ Positive } & \multicolumn{2}{|c|}{ Positive } \\
\hline \multirow{2}{*}{$397 \mathrm{a} 12$} & 24.47 & 24.18 & 23.31 & 23.09 & 21.79 & 22.78 & 22.87 & 21.27 & 20.86 & 22.10 & 21.41 \\
\hline & \multicolumn{2}{|c|}{ Positive } & \multicolumn{3}{|c|}{ Positive } & & tive & & ive & Po & ive \\
\hline & 20.64 & 19.69 & 19.62 & 18.8 & 17.19 & 18.34 & 18.95 & 17.82 & 16.31 & 18.69 & 17.96 \\
\hline & Pos & & & Positiv & & & tive & & ive & Po & ive \\
\hline & N/A & N/A & 40.98 & N/A & 36.66 & 40.18 & 36.14 & 36.55 & 33.62 & 33.18 & 34.32 \\
\hline & $\mathrm{Neg}$ & tive & & Positiv & & & tive & & ive & Po & ive \\
\hline & 23.99 & 24.81 & 23.92 & 24.06 & 24.94 & 23.77 & 23.45 & 22.18 & 23.84 & 27.37 & 22.21 \\
\hline & Pos & & & Positiv & & & tive & & ive & Po & ive \\
\hline & 32.46 & 33.25 & 32.22 & 33.44 & 32.72 & 32.37 & 32.09 & 30.15 & 31.21 & 31.40 & 30.80 \\
\hline & Pos & & & Positiv & & & tive & & ive & Po & ive \\
\hline & 26.08 & 26.82 & 25.48 & 26.09 & 25.88 & 25.63 & 25.5 & 23.79 & 24.83 & 24.88 & 24.15 \\
\hline & Pos & & & Positiv & & & tive & & ive & Po & ive \\
\hline & N/A & N/A & 35.24 & 40.6 & 34.39 & 35.27 & 34.39 & 32.34 & 32.11 & 33.17 & 32.95 \\
\hline & Neg & tive & & Positiv & & & tive & & ive & Po & ive \\
\hline & N/A & N/A & 38.76 & N/A & 36.07 & 37.85 & 36.8 & 34.01 & 33.43 & 33.94 & 34.17 \\
\hline & Neg & tive & & Positiv & & & tive & & ive & Po & ive \\
\hline & N/A & N/A & 36.56 & N/A & 35.02 & 37.77 & 36.05 & 33.09 & 33.09 & 34.60 & 34.25 \\
\hline & $\mathrm{Neg}$ & tive & & Positiv & & & tive & & ive & Po & ive \\
\hline & N/A & N/A & N/A & N/A & N/A & N/A & N/A & N/A & N/A & N/A & N/A \\
\hline & $\mathrm{Neg}$ & tive & & Jegati & & $\mathrm{Ne}$ & ative & $\mathrm{Ne}$ & tive & $\mathrm{Ne}$ & tive \\
\hline & N/A & N/A & N/A & N/A & N/A & N/A & $\mathrm{N} / \mathrm{A}$ & N/A & N/A & 35.92 & N/A \\
\hline & Neg & tive & & Jegati & & $\mathrm{Ne}$ & ative & $\mathrm{Ne}$ & tive & Po & ive \\
\hline & N/A & N/A & N/A & N/A & N/A & N/A & N/A & N/A & N/A & $\mathbf{N} / \mathbf{A}$ & 37.71 \\
\hline & Neg & tive & & Jegati & & $\mathrm{Ne}$ & ative & $\mathrm{Ne}$ & tive & Po & ive \\
\hline
\end{tabular}

"Bosphor, positive - Cq below 35.0 for both or only one SARS-CoV-2 gene; "Gene Finder, positive - Cq below 43.0 for at least two SARS-CoV-2 genes; "DiaPlexQ, positive - Cq below 40 for both or only one SARS-CoV-2 gene; "Vazyme, positive $-\mathrm{Cq}$ below 38 for both or only one SARS-CoV-2 gene; ${ }^{* *}$ MediPAN, positive - Cq below 38.0 for both SARS$\mathrm{CoV}-2$ genes, in case of Cq below 38.0 fo only one gene, it is recommended to repeat swab collection and test within two next days or according to WHO to perform the analysis with different method, such as sequencing. 
Bogusław Tymoniuk, Paweł Zmora, Julia Latowska et al.

Table III. Comparison of Cq value and diagnostic results for the chosen samples analysed with selected PCR systems Tabela III. Porównanie wartości Cq oraz wyników diagnostycznych wybranych próbek przy użyciu dwóch aparatów

\begin{tabular}{|c|c|c|c|c|c|c|c|c|}
\hline & \multicolumn{4}{|c|}{ DiaPlexQ* } & \multicolumn{4}{|c|}{ MediPAN $^{* *}$} \\
\hline \multirow{2}{*}{ Sample } & \multicolumn{2}{|c|}{ Biorad CFX96 } & \multicolumn{2}{|c|}{ Agilent AriaMx } & \multicolumn{2}{|c|}{ Biorad CFX96 } & \multicolumn{2}{|c|}{ Agilent AriaMx } \\
\hline & $\mathrm{N}$ & ORF1a & $\mathrm{N}$ & ORF1a & ORF1ab & S & ORFlab & S \\
\hline \multirow{2}{*}{$397 \mathrm{a} 8$} & 29.26 & 27.56 & 24.4 & 24.87 & 26.44 & 26.01 & 25.74 & 24.03 \\
\hline & \multicolumn{2}{|c|}{ Positive } & \multicolumn{2}{|c|}{ Positive } & \multicolumn{2}{|c|}{ Positive } & \multicolumn{2}{|c|}{ Positive } \\
\hline \multirow{2}{*}{$397 \mathrm{a} 9$} & 37.7 & 34.43 & 28.75 & 29.36 & 32.71 & 31.86 & 31.19 & 28.82 \\
\hline & \multicolumn{2}{|c|}{ Positive } & \multicolumn{2}{|c|}{ Positive } & \multicolumn{2}{|c|}{ Positive } & \multicolumn{2}{|c|}{ Positive } \\
\hline \multirow{2}{*}{$397 \mathrm{a} 10$} & 37.95 & 36.18 & 34.81 & 33.92 & 33.64 & 32.89 & 32.9 & 31.07 \\
\hline & \multicolumn{2}{|c|}{ Positive } & \multicolumn{2}{|c|}{ Positive } & \multicolumn{2}{|c|}{ Positive } & \multicolumn{2}{|c|}{ Positive } \\
\hline \multirow{2}{*}{$397 \mathrm{a} 12$} & 22.78 & 22.87 & 18.99 & 20.29 & 22.10 & 21.41 & 21.68 & 20.11 \\
\hline & \multicolumn{2}{|c|}{ Positive } & \multicolumn{2}{|c|}{ Positive } & \multicolumn{2}{|c|}{ Positive } & \multicolumn{2}{|c|}{ Positive } \\
\hline \multirow{2}{*}{$397 \mathrm{a} 13$} & 18.34 & 18.95 & 14.62 & 16.35 & 18.69 & 17.96 & 18.77 & 16.97 \\
\hline & & & & & & & & \\
\hline & 40.18 & 36.14 & 39.19 & 33.98 & 33.18 & 34.32 & 36.42 & 36.57 \\
\hline (1) & & & & & & & & \\
\hline & 23.77 & 23.45 & 21.22 & 21.65 & 27.37 & 22.21 & 30.91 & 21.82 \\
\hline & & & & & & & & \\
\hline 207064 & 32.37 & 32.09 & 28.84 & 29.26 & 31.40 & 30.80 & 31.79 & 30.16 \\
\hline & & & & & & & & \\
\hline & 25.63 & 25.5 & 23.06 & 23.69 & 24.88 & 24.15 & 25.83 & 23.68 \\
\hline & & & & & & & & \\
\hline 20700 & 35.27 & 34.39 & 30.49 & 31.43 & 33.17 & 32.95 & 34.44 & 32.55 \\
\hline & & & & & & & & \\
\hline & 37.85 & 36.8 & 34.1 & 33.68 & 33.94 & 34.17 & 35.89 & 33.98 \\
\hline & & & & & & & & \\
\hline 30700 & 37.77 & 36.05 & 34.76 & 37.49 & 34.60 & 34.25 & 34.77 & 33.99 \\
\hline & & & & & & & & \\
\hline & $\mathrm{N} / \mathrm{A}$ & N/A & N/A & N/A & N/A & N/A & N/A & N/A \\
\hline & & & & & & & & \\
\hline & N/A & N/A & 38.16 & N/A & 35.92 & N/A & N/A & N/A \\
\hline ד & & & & & & & & \\
\hline & N/A & N/A & N/A & N/A & N/A & 37.71 & N/A & N/A \\
\hline & & & & & & & & \\
\hline
\end{tabular}

"DiaPlexQ, positive - Cq below 40 for both or only one SARS-CoV-2 gene; "*MediPAN, positive - Cq below 38.0 for both SARS-CoV-2 genes, in case of Cq below 38.0 for only one gene, it is recommended to repeat swab collection and test within two next days or according to WHO to perform the analysis with different method, such as sequencing. 
In addition, during the study, we compared two different real-time PCR platforms: AriaMx Real-Time PCR System (Agilent) and CFX96 Touch Real-Time PCR Detection System (Biorad). For Bosphore Novel Coronavirus (2019-nCoV) Detection Kit, VIASURE SARS-CoV-2 Real Time PCR Detection Kit, and Vazyme 2019-Novel Coronavirus (2019-nCoV) Triplex RT-qPCR, no differences in the diagnostic results were observed.

In the case of the DiaPlexQ ${ }^{\mathrm{TM}}$ Novel Coronavirus and MediPAN 2G+ FAST COVID tests, differences in the diagnostic result depending on the used test and the PCR platform were shown for two samples, i.e. $397 \mathrm{a} 14$ and 397a15 (Table III). The obtained results clearly show that the greatest difficulties in the diagnosis of SARS-CoV-2 infection are caused by samples with a low viral load and late amplification of the viral genetic material.

\section{SUMMARY}

The strategy to combat an epidemic caused by viruses, bacteria or fungi is based, among others, on: (i) identification of the pathogen, (ii) limiting its spread, (iii) finding effective drugs, and (iv) developing an effective vaccine to prevent infection (1).

In case of an ongoing pandemic, SARS-CoV-2 was identified as the cause of severe respiratory syndrome as early as January 2020 (12) but no effective drug has yet been found that could save the lives of people with severe COVID-19 (13). On the other hand, several vaccines have been developed to effectively protect against SARS-CoV-2 infection and the severe course of COVID-19 (14-17). Unfortunately, due to production limitations, huge demand in virtually every country in the world and the lack of knowledge of how long protection is provided by the developed vaccines, it is estimated that achieving population immunity can be a huge challenge and take at least several months (18). For this reason, in order to effectively fight the COVID-19 pandemic, the worldwide efforts should focus on limiting the spread of SARS-CoV-2 by compliance to sanitary and epidemiological restrictions (using mouth and nose masks, frequent disinfection of hands and maintaining social distance), isolation of infected patients as well as persons who had direct contact with them, and mass screening of the general public.

Currently, there are many molecular tests based on the RT-PCR reaction for detecting SARS-CoV-2 infection on the Polish as well as European marker. As shown in this article, the main differences between these tests are the limit of virus detection and the reaction time. These differences are also emphasized by other authors $(19,20)$, which clearly indicates that termocyklera AriaMx (Agilent). Natomiast obecność SARS-CoV-2 w próbce $397 \mathrm{a} 15$ nie została potwierdzona przy pomocy innych zestawów diagnostycznych, a ilość materiału nie pozwoliła na sekwencjonowanie, co może sugerować wynik fałszywie dodatni spowodowany np. przez zanieczyszczenie próbki. Uzyskane wyniki mogą_świadczyć o wyższej czułości zestawów MediPAN i DiaPlexQ, zgodnie z informacjami producentów, w porównaniu z pozostałymi badanymi zestawami diagnostycznymi. Z kolei wysoka liczba wyników fałszywie ujemnych w przypadku zastosowania zestawu Bosphore może wskazywać na niższą czułość tego testu w porównaniu z pozostałymi. Może to wynikać z ograniczonej liczby cykli reakcji PCR zalecanej przez producenta $\mathrm{w}$ instrukcji użytkowania testu, tj 35, oraz niskiego miana wirusa w części wymazów (Tab. II). Ponadto, w trakcie badań porównano wyniki testów na obecność SARS-CoV-2 otrzymywane przy użyciu dwóch różnych platform: AriaMx Real-Time PCR System (Agilent) oraz CFX96 Touch Real-Time PCR Detection System (Biorad). W przypadku zestawów Bosphore Novel Coronavirus (2019-nCoV) Detection Kit, VIASURE SARS-CoV-2 Real Time PCR Detection Kit oraz Vazyme 2019-Novel Coronavirus (2019-nCoV) Triplex RT-qPCR nie zaobserwowano żadnych różnic pomiędzy urządzeniami. Natomiast, w przypadku testów DiaPlexQ ${ }^{\mathrm{TM}}$ Novel Coronavirus oraz MediPAN 2G+ FAST COVID wykazano różnice w wyniku diagnostycznym w zależności od stosowanego testu oraz platformy PCR dla dwóch próbek, tj. 397 a14 oraz 397 a15 (Tab. III). Uzyskane wyniki wyraźnie pokazują, iż najwięcej trudności w diagnostyce zakażenia SARS-CoV-2 sprawiają próbki o niskim mianie wirusa, w przypadku których obserwujemy późną amplifikację materiału genetycznego wirusa.

\section{PODSUMOWANIE}

Strategia walki z epidemią wywołaną przez wirusy, bakterie lub grzyby, opiera się między innymi na: (i) identyfikacji czynnika chorobotwórczego, (ii) ograniczeniu jego rozprzestrzeniania się, (iii) znalezieniu skutecznych leków oraz (iv) opracowaniu skutecznej szczepionki zapobiegającej zakażeniu (1). W przypad$\mathrm{ku}$ trwającej obecnie pandemii, SARS-CoV-2 został zidentyfikowany jako powód ciężkiego zespołu oddechowego już w styczniu 2020 roku (12) jednakże do tej pory nie znaleziono skutecznego leku, który mógłby ratować życie osób z ciężką postacią COVID-19 (13). Opracowano natomiast szczepionki skutecznie chroniące przed zakażeniem SARS-CoV-2 oraz ciężkim przebiegiem COVID-19 (14-17). Niestety, ze względu na ograniczenia produkcyjne, ogromne zapotrzebowanie w praktycznie każdym kraju świata oraz brak wiedzy jak długą ochronę zapewniają opracowane 
these parameters should be mainly taken into account when choosing and purchasing diagnostic tests

It should also be emphasized that the result of the RT-PCR test may be affected by many factors, such as the method of swab collection, transport of samples from the swab point to the laboratory, the composition of the transport medium or the method of isolating the genetic material $(5,6,21)$. In our opinion, the result of the diagnostic test ('positive' or 'negative') should be supplemented with the Ct value, in line with the suggestions of other scientists (22). Virus detection in samples with a high $\mathrm{Ct}$ value is of great importance in controlling the SARS-CoV-2 epidemic, as it allows the identification of people in the early stages of infection who may be the source of the virus spreading in the environment. An insufficiently sensitive test can give a negative result and thus increase the risk of virus transmission. The recommendation to repeat the test after a few days may eliminate from this subgroup people in the final stage of infection, freeing them from the need for further isolation.

Moreover, it should be remembered that the $\mathrm{Ct}$ parameter does not directly translate into clinical symptoms. There are cases of poorly symptomatic people with a high $\mathrm{Ct}$ value, as well as symptomatic patients with a lower Ct value (after the 30 th cycle) (19). On the other hand, the high sensitivity of diagnostic kits increases the risk of so-called false-positive results, e.g. caused by contamination of the test sample (23). Currently, there is a discussion in the scientific and medical community on the interpretation of the socalled low positive results, e.g. detection of only one of the two viral genes or high Cq value above cycle 35, as well as on the consequences of false positive/negative results (23-25). Surkova and colleagues indicate that false positive results may be associated with such consequences as the cancellation of a planned medical procedure, loss of income, incorrect estimates of the epidemic development and inadequate introduction of additional sanitary and epidemiological restrictions (26). On the other hand, it should be highlighted that false-negative results as a consequence of e.g. low sensitivity of the diagnostic kit or bad storage of the collected material may have much more catastrophic consequences, with new epidemic outbreaks and another wave of new infections (23). Therefore, the WHO recommends careful analysis of molecular test results by trained and experienced laboratory diagnosticians. szczepionki, szacuje się, że osiągnięcie odporności populacyjnej może być ogromnym wyzwaniem oraz zająć co najmniej kilka-kilkanaście miesięcy (18). $\mathrm{Z}$ tego powodu $\mathrm{w}$ celu efektywnej walki $\mathrm{z}$ pandemią COVID-19, nasze wysiłki powinny skupiać się na ograniczeniu rozprzestrzeniania się SARS-CoV-2 poprzez stosowanie się do obostrzeń sanitarno-epidemiologicznych (stosowanie maseczek zakrywających usta i nos, częsta dezynfekcja dłoni oraz utrzymywanie dystansu społecznego), izolacji osób zakażonych i mających kontakt z osobą zakażoną oraz masowego przesiewowego testowania całego społeczeństwa.

Obecnie, zarówno na polskim jak i europejskim rynku, dostępnych jest wiele testów wykrywających zakażenie SARS-CoV-2 opartych o reakcję RT-PCR. Jak wykazano w niniejszym artykule, testy te różnią się między sobą głównie limitem detekcji wirusa oraz czasem trwania reakcji. Różnice te podkreślane są również przez innych autorów $(19,20)$, co jednoznacznie wskazuje, iż te parametry powinny być głównie brane pod uwage przy wyborze oraz zakupie testów diagnostycznych.

Należy również podkreślić, iż na wynik testu RT -PCR może wpływać wiele czynników, takich jak sposób pobrania wymazu, transport próbek z punktu wymazowego do laboratorium, skład medium transportowego czy też sposób izolacji materiału genetycznego $(5,6,21)$. Naszym zdaniem wynik testu diagnostycznego ('pozytywny' lub 'negatywny') powinien być uzupełniony o wartość $\mathrm{Ct}$, zgodnie z sugestiami także innych naukowców (22). Detekcja wirusa w próbkach o wysokiej wartości Ct ma ogromne znaczenie w kontroli epidemii SARS-CoV-2, ponieważ pozwala identyfikować osoby znajdujące się we wczesnej fazie zakażenia, które mogą być źródłem rozprzestrzeniania się wirusa w otoczeniu. Niewystarczająco czuły test da w takim przypadku wynik negatywny, zwiększając ryzyko transmisji wirusa. Zalecenie powtórzenia badania po kilku dniach pozwoli z kolei wyeliminować $\mathrm{z}$ tej podgrupy osoby w końcowej fazie infekcji, zwalniając je z konieczności dalszej izolacji. Poza tym należy pamiętać, że parametr $\mathrm{Ct}$ nie przekłada się bezpośrednio na objawy kliniczne. Zdarzają się przypadki osób skąpo objawowych z wysoką wartością $\mathrm{Ct}$, a także osób chorujących z późniejszą wartością $\mathrm{Ct}$ (po 30 cyklu) (19). Z drugiej strony, wysoka czułość zestawów diagnostycznych zwiększa ryzyko tzw. wyników fałszywie dodatnich, spowodowanych np. przez zanieczyszczenie badanej próby (23). Obecnie w środowisku naukowym i medycznym trwa dyskusja nad interpretacją tzw. wyników słabopozytywnych, $n p$. wykrycie tylko jednego $z$ dwóch genów wirusa lub wysoka wartość Cq powyżej 35 cyklu oraz nad konsekwecjami wyników fałszywie dodatnich/ujemnych (23-25). Surkova i wsp. wskazują, iż wyniki fałszywie 


\section{REFERENCES}

1. WHO | World Health Organization. https://www. who.int/

2. Troeger C, Blacker B, Khalil IA, et al. Estimates of the global, regional, and national morbidity, mortality, and aetiologies of lower respiratory infections in 195 countries, 1990-2016: a systematic analysis for the Global Burden of Disease Study 2016. Lancet Infect Dis 2018;18(11):1191-210.

3. Choroby zakaźne i zatrucia w Polsce - 2018 r. http://wwwold.pzh.gov.pl/oldpage/epimeld/2018/ index mp.html

4. Abdelrahman Z, Li M, Wang X. Comparative Review of SARS-CoV-2, SARS-CoV, MERS$\mathrm{CoV}$, and Influenza A Respiratory Viruses. Front Immunol 2020;11: 552909.

5. Kubina R, Dziedzic A. Molecular and Serological Tests for COVID-19. A Comparative Review of SARS-CoV-2 Coronavirus Laboratory and Pointof-Care Diagnostics. Diagnostics 2020;10(6):434.

6. Pang J, Wang MX, Ang IYH, et al. Potential Rapid Diagnostics, Vaccine and Therapeutics for 2019 Novel Coronavirus (2019-nCoV): A Systematic Review. J Clin Med 2020;9(3):623.

7. Rastawicki W, Rokosz-Chudziak N. Characteristics and assessment of the usefulness of serological tests in the diagnostic of infection caused by coronavirus SARS-CoV-2 on the basis of available manufacturer's data and literature review. Przegl Epidemiol 2020;74(1):113-32.

8. Lisboa Bastos M, Tavaziva G, Abidi SK, et al. Diagnostic accuracy of serological tests for covid-19: Systematic review and meta-analysis. BMJ 2020;370:2516.

9. Murphy J, Bustin SA. Reliability of real-time reverse-transcription PCR in clinical diagnostics: Gold standard or substandard? Expert Rev Mol Diagn 2009;9:187-97.

10. Watzinger F, Ebner K, Lion T. Detection and monitoring of virus infections by real-time PCR. Mol Aspects Med 2006;27:254-98.

11. Narodowy Instytut Zdrowia Publicznego Państwowy Zakład Higieny. https://www.pzh.gov. $\mathrm{pl} /$

12. Zhu N, Zhang D, Wang W, et al. A Novel Coronavirus from Patients with Pneumonia in China, 2019. N Engl J Med 2020;382(8):727-33.

13. Wang Y, Zhang D, Du G, et al. Remdesivir in adults with severe COVID-19: a randomised, doubleblind, placebo-controlled, multicentre trial. Lancet 2020;395(10236):1569-78.

14. Polack FP, Thomas SJ, Kitchin N, et al. Safety and Efficacy of the BNT162b2 mRNA Covid-19 Vaccine. N Engl J Med 2020;383(27):2603-15. dodatnie mogą być związane z takimi konsekwencja$\mathrm{mi}$, jak anulowanie planowanego zabiegu medycznego, utrata dochodów, błędnymi szacunkami rozwoju epidemii oraz nieadekwatnym wprowadzeniem dodatkowych obostrzeń sanitarno-epidemiologicznych (26). $Z$ drugiej strony, należy mieć na uwadze, że wyniki fałszywie ujemne będące konsekwencją np. niskiej czułości zestawu diagnostycznego lub złego przechowywania pobranego materiału, mogą mieć zdecydowanie bardziej katastrofalne skutki w postaci powstawania kolejnych ognisk epidemicznych oraz kolejnej fali nowych zakażeń (23). Stąd, Światowa Organizacja Zdrowia rekomenduje ostrożną, aczkolwiek wnikliwą analizę wyników testów molekularnych przez wyszkolonych i doświadczonych diagnostów laboratoryjnych.

15. Baden LR, El Sahly HM, Essink B, et al. Efficacy and Safety of the mRNA-1273 SARS-CoV-2 Vaccine. N Engl J Med 2021;384(5):403-16.

16. Voysey M, Clemens SAC, Madhi SA, et al. Safety and efficacy of the ChAdOx1 nCoV-19 vaccine (AZD1222) against SARS-CoV-2: an interim analysis of four randomised controlled trials in Brazil, South Africa, and the UK. Lancet 2021;397(10269):99-111.

17. Logunov DY, Dolzhikova I V, Shcheblyakov D V, et al. Safety and efficacy of an rAd26 and rAd5 vector-based heterologous prime-boost COVID-19 vaccine: an interim analysis of a randomised controlled phase 3 trial in Russia. Lancet 2021;20:671-681.

18. Anderson RM, Vegvari C, Truscott J, Collyer BS. Challenges in creating herd immunity to SARSCoV-2 infection by mass vaccination. Lancet 2020;396:1614-6.

19. Carroll A, McNamara E. Comparison and correlation of commercial SARS-CoV-2 real-timePCR assays, Ireland, June 2020. Eurosurveillance 2021;26(6):2002079.

20. van Walle I, Leitmeyer $\mathrm{K}$, Broberg EK. Meta-analysis of the clinical performance of commercial SARS-CoV-2 nucleic acid, antigen and antibody tests up to 22 August 2020. medRxiv 2020:2020.09.16.20195917.

21. Yip CCY, Sridhar S, Cheng AKW, et al. Evaluation of the commercially available LightMix ${ }^{\circledR}$ Modular E-gene kit using clinical and proficiency testing specimens for SARS-CoV-2 detection. J Clin Virol. 2020;129:104476.

22. Tom MR, Mina MJ. To Interpret the SARS-CoV-2 Test, Consider the Cycle Threshold Value. Clin Infect Dis 2020;71(16):2252-4.

23. Tang YW, Schmitz JE, Persing DH, Stratton CW. Laboratory diagnosis of COVID-19: 
Current issues and challenges. J Clin Microbiol 2020;58(6):e00512-20

24. Vandenberg $O$, Martiny $D$, Rochas $O$, van Belkum A, Kozlakidis Z. Considerations for diagnostic COVID-19 tests. Nature Rev Microbiol 2021;19:171-83.

25. Asai T. COVID-19: accurate interpretation of diagnostic tests - a statistical point of view. J Anesth. Springer Japan; 2020;1:1

26. Surkova E, Nikolayevskyy V, Drobniewski F. False-positive COVID-19 results: hidden problems and costs. Lancet Respir Med 2020;8:1167-8.
Received: 05.03.2021

Otrzymano: 05.03.2021 r.

Accepted for publication: 11.05.2021

Zaakceptowano do publikacji: 11.05.2021 r.

\section{Correspondence authors:}

Adres do korespondencji:

Dr Paweł Zmora

Institute of Bioorganic Chemistry PAS

ul. Noskowskiego 12/14, 61-704 Poznań

email: pzmora@ibch.poznan.pl

tel. 618528503 int. 1142 